\title{
Copyright $\odot$
}

Es gilt deutsches Urheberrecht.

Das Hochschulschrift darf zum eigenen Gebrauch kostenfrei heruntergeladen, konsumiert, gespeichert oder ausgedruckt, aber nicht im Internet bereitgestellt oder an Außenstehende weitergegeben werden ohne die schriftliche Einwilligung des Urheberrechtsinhabers. Es ist nicht gestattet, Kopien oder gedruckte Fassungen der freien Onlineversion zu veräußern.

German copyright law applies.

Copyright and Moral Rights for this thesis are retained by the author and/or other copyright owners. The work or content may be downloaded, consumed, stored or printed for your own use but it may not be distributed via the internet or passed on to external parties without the formal permission of the copyright holders. It is prohibited to take money for copies or printed versions of the free online version. 


\title{
A Coupled High Resolution Atmosphere - Ocean Model for the BALTEX Region
}

\author{
Renate_Hagedom, Institut für Meereskunde, Düstembrooker Weg 20, D-24105 Kiel, Germany, \\ e-mail: rhagedom@ifm.uni-kiel.de
}

Daniela Jacob, Max-Planck-Institut für Meteorologie, Bundesstraße 55, D-20146 Hamburg, Germany

Andreas Lehmann, Institut für Meereskunde, Düsternbrooker Weg 20, D-24105 Kiel, Germany

The major objective of the BALTEX program is to provide validated, coupled modelling tools for explaining and predicting the energy and water processes in the climate system, consisting of the atmosphere, continental surfaces and the ocean (International BALTEX Secretariat, 1997). To contribute to this aim, the atmospheric regional model (REMO) from Max-Planck-Institute for Meteorology has been coupled to the Kiel Baltic Sea model (BSMO). The 3-dimensional atmospheric model REMO is based on the Europa-Modell (EM), the main weather forecast model of the German Weather Service (DWD). It is used in the so-called climate mode, i.e. during the whole integration only the lateral boundary fields were updated every 6 hours (Jacob et al., 1997). The horizontal resolution is $1 / 6^{\circ}$ on the rotated longitude/latitude grid, this is equivalent to approximately $18 \times 18 \mathrm{~km}^{2}$. The vertical distribution of the 20 model levels is the same as in the EM. The Kiel Baltic Sea Model is a 3-dimensional eddy-resolving baroclinic model with a horizontal resolution of approximately $5 \times 5 \mathrm{~km}^{2}$ and a discretization of 28 levels in the vertical (Lehmann, 1995). Until now, these two models have been run seperately and both were forced with DWD analyses or forecasts, respectively.

As a first step towards a fully coupled system some sensitivity studies have been done varying the surface boundary conditions in both models. The simulations were performed for the PIDCAP period from August to October 1995. Firstly, REMO was run by using DWD analyses as boundary conditions. Atmospheric parameters produced by this run were used as forcing for the Kiel Baltic Sea Model. For a further run of REMO we replaced the DWD-SSTs in the BALTEX region with BSMO-SSTs achieved from the previous run. These BSMO-SSTs are in some situations, when rapid cooling occurs, quite different from DWD-SSTs and closer to satellite observed SSTs (Fig. 1, lower panel). As a result of these changed lower boundary condition, among other things, REMO calculated heat fluxes are different (Fig. 1, upper panel). From the end of August to the beginning of September major changes occured in the eastern Gotland Basin. For instance on August 31 st a difference of $3^{\circ} \mathrm{C}$ in SST causes a reduced latent heat flux of $200 \mathrm{Wm}^{-2}$. According to that, also precipitation is reduced in this region. Whereas the different SSTs have only a slight effect on the dynamic variables.

The next step was the development of a fully coupled model system. Therefore the Baltic Sea model was incorporated into REMO as an optional subroutine. The interface between both models organizes the exchange of the mutual forcing at the common boundary. That means the interface has to provide REMO calculated heat fluxes, radiation fluxes, wind stresses, precipitation and mean sea level pressure on the BSMO grid, as well as the BSMO calculated SSTs on the REMO grid. The frequency of information exchange can freely be chosen and was set to 6 hours in the first coupled run. The SSTs from the coupled run show a similar behaviour compared to the BSMO-SSTs from the experiment with no feedback to the forcing fields (Fig. 1, lower panel). On the one hand this indicates that - in this experiment - mainly minor changes in the dynamic variables of the atmospheric model occur due to different SSTs. On the other hand this points out that the Baltic Sea model responses reasonably to the REMO calculated fluxes. This is not obvious, because until now the BSMO was forced by atmospheric variables and the flux calculation routines in the Baltic Sea model are not exactly the same as in REMO. Thus it is a good result that the Baltic Sea model has no drift when it's forced by REMO fluxes instead of atmospheric variables and the coupling was realized without any flux corrections. Finally, we have to remark that another reason for the non existing drift in the coupled system could be the strong constraint of lateral boundary conditions for the atmospheric model. Further we don't know whether the coupled model shows a drift during longer simulation periods. Therefore we have to extent our experiments to longer runs with different atmospheric conditions. 


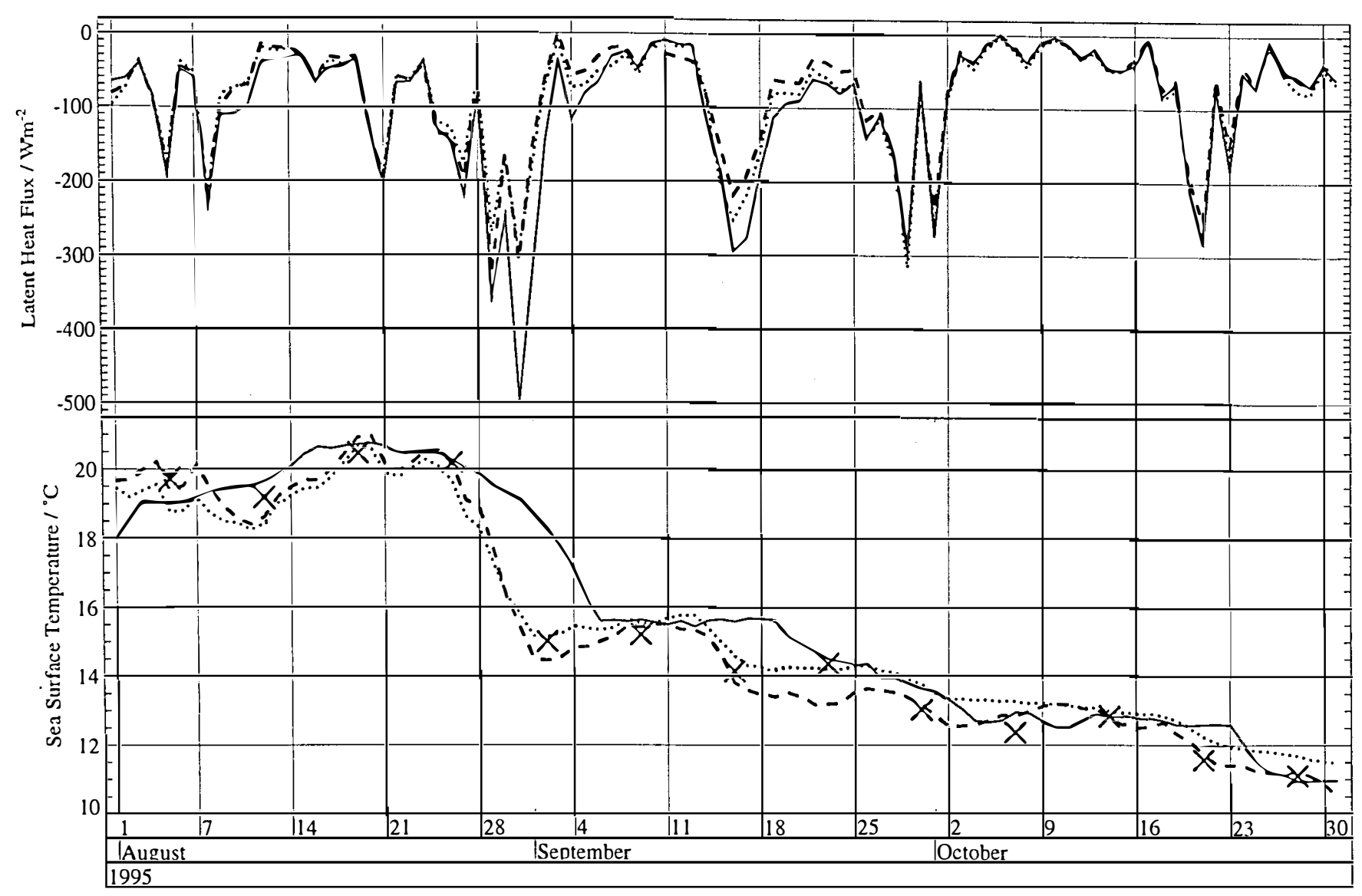

Figure 1: (Lower panel) Sea Surface Temperatures (SST), crosses: satellite observed SST from weekly charts, solid line: SST from DWD analyses $\left(0.5^{\circ} \mathrm{EM}\right)$, dotted line: SST from BSMO (forced by REMO) dashed line: SST from the coupled run. (Upper panel) REMO calculated latent heat flux (LHF) mean over 6:00 to 12:00, solid line: LHF from the first run with DWD-SST, dotted line: LHF from the second run with BSMO-SST, dashed line: LHF from the coupled run. All values are means over a $1^{\circ} \times 2^{\circ}$ wide region in the eastern Gotland Basin.

\section{References:}

Int. BALTEX Secretariat, 1997: The Main BALTEX Experiment 1999-2001 - BRIDGE. Strategic Plan. Pub. No. 9, 78 pages

Jacob, D., Podzun, R., 1997: Sensitivity Studies with the Regional Climate Model REMO. Meteorol. Atmos. Phys., 63, $119-129$

Lehmann, A., 1995: A three-dimensional baroclinic eddy-resolving model of the Baltic Sea. TELlus, 47A, 1013 - 1031 